\title{
Fasciola Hepatica and other Helminths in Goats in Puerto Rico'
}

\author{
Bendezú, P., Frame, A. D., Muñoz, R., ${ }^{2}$ Cabezas, J., Hurd, J., Frame, E., \\ Planas, D., Alemán, A. and Gordo, $V$.
}

ABSTRACT

Fecal examination of 769 goats taken in 1981 from 48 farms in 30 municipalities located throughout Puerto Rico, showed 10 helminths to be common in these goats. The study showed 1.43 percent of these to be positive with Fasciola hepatica eggs. The other helminth eggs found and percent rates of infection were as follows: Oesophagostomum columbianum 65.67, Haemonchus contortus 56.31, Bunostomum trigonocephalum 46.94, Chabertia ovina 24.57, Trichostrongylus capricola 15.60, Ostertagia circumcincta 14.43, Trichuris ovis 10.14, Moniezia expansa 6.39, and Cooperia curticei with 2.21 percent. The intensity ranged from 5 eggs per gram of stool sample as in the case of $F$. hepatica to 1,500 eggs per gram in $T$. capricola samples. Moreover, $68.7 \%$ of the goats sampled showed concurrent infections of two to eight different parasite species per goat.

\section{INTRODUCTION}

There are few reports on $F$. hepatica in goats in Puerto Rico (11). Bagué in 1921 (1) observed fascioliasis in swine and cattle and found only one goat infected. Volkenberg $(15,16,17,18,19)$ reported finding $F$. hepatica in cattle, goats, and horses living in the wetlands of the Island. This was reviewed by Hillyer (11).

Most of the reports on animal fascioliasis in Puerto Rico refer to this parasitism in cattle. Chiriboga et al. $(3,4)$ and de León et al. $(5,6,7)$ described fascioliasis in cattle particularly in the area of Arecibo. Frame and Bendezú $(8,9)$ reported that the number of infected cattle slaughtered at the slaughterhouses had risen from $7.5 \%$ in $1948-49$ to $31.75 \%$ by 1976 (12). A subsequent study of nearly 3000 dairy cows from 40 farms throughout the Island showed $65 \%$ of these to be positive for $F$. hepatica (10).

The rise in fascioliasis in cattle through the years and the scant data regarding this disease in goats encouraged us to undertake this study to determine the extent of this parasitism in these animals.

${ }^{\text {I }}$ Manuscript submitted to Editorial Board November 24, 1982. The research was supported by U.S. Public Health Grant RR-8159 (AF, PB) administered through the Division of Research Resources National Institutes of Minority Biomedical Research Support.

${ }^{2}$ Veterinarian, Parasitologist and Statistician, respectively Interamerican University of Puerto Rico, San Juan, P.R. The authors wish to thank Dr. George V. Hillyer, Department of Biology-Immunology, Univeristy of Puerto Rico, for his advice; Dr. Angel David Cruz, Geographer, University of Puerto Rico, for the map and Dr. Delfín de León, Department of Animal Industry of the Agricultural Experiment Station of the University of Puerto Rico for his assistance in the identification of the parasites. 


\section{MATERIALS AND METHODS}

The Island was scanned for goat farms using a list obtained from the Society of Goat Farmers and word of mouth as a guide. Forty eight goat farms in 30 municipalities were visited. The random sample used for the selection of the towns and farms covered the entire Island. The majority of farms with goats were small and family operated rather than commercial enterprises. In some cases there were not more than two or three goats on what was considered a "finca." The selection of goats, however, proved to be a greater challenge as the fecal samples were obtained rectally by the researchers.

The stools collected were taken to our laboratory where each sample

TABLE 1.-Helminths in goats in Puerto Rico

\begin{tabular}{|c|c|c|c|c|}
\hline \multirow{2}{*}{ Parasites } & \multirow{2}{*}{$\begin{array}{l}\text { Number } \\
\text { with } \\
\text { parasite }\end{array}$} & \multicolumn{2}{|c|}{$\begin{array}{c}\text { Intensity } \\
\text { Eggs per gram }\end{array}$} & \multirow{2}{*}{$\begin{array}{l}\text { Percent } \\
\text { Infected }\end{array}$} \\
\hline & & Min. & Max. & \\
\hline Oesophagostomum columbianum & 499 & 100 & 850 & 65.67 \\
\hline Haemonchus contortus & 433 & 250 & 980 & 56.31 \\
\hline Bunostomum trigonocephalum & 355 & 20 & 60 & 46.94 \\
\hline Chabertia ovina & 189 & 35 & 72 & 24.57 \\
\hline Trichostrongylus capricola & 119 & 78 & 1,500 & 15.60 \\
\hline Ostertagia circumcincta & 111 & 11 & 45 & 14.43 \\
\hline Trichuris ovis & 77 & 50 & 1,400 & 10.14 \\
\hline Moniezia expansa & 46 & 90 & 1,300 & 6.39 \\
\hline Cooperia curticei & 17 & 120 & 350 & 2.21 \\
\hline Fasciola hepatica & 11 & 5 & 31 & 1.43 \\
\hline Total no. of goats sampled & 769 & & & \\
\hline
\end{tabular}

was processed by the sedimentation method for trematode eggs, and by the centrifugal-floatation method with a saturated sugar solution for the nematode eggs $(2,13,14)$. A 0.5 methyl green staining technique described by de León et al. (5) was used to stain the fecal debris but not the eggs prior to microscopic examination. The intensity of infection was determined by counting all the eggs present in each sample. Identification of the genera and species was based on observation of the adult and the egg.

\section{RESULTS AND DISCUSSION}

Coprological examination of 769 goats taken from 48 farms in 30 municipalities located throughout the Island, showed the presence of 10 different helminths in these goats. In addition, almost $70 \%$ of the goats sampled had concurrent infections from two to eight different helminths in one host.

Table I shows the parasite eggs found and percentage rates of infection 
with intensities. Fasciola hepatica shows the lowest rate of infection with $1.43 \%$.

The low rate of fascioliasis in the goats sampled contrasted with the high rate of this parasite reported in a similar study conducted in dairy cattle in 1978 (10), where $F$. hepatica was found in $65 \%$ of the cows sampled. In cattle, however, $H$. contortus was found in only $17.7 \%$ of the samples. ${ }^{3}$

Many of the goats in this study grazed on the dry high lands along the mountain side rather than the lowlands generally grazed by cattle. This could be a possible explanation for the low fascioliasis in the goats

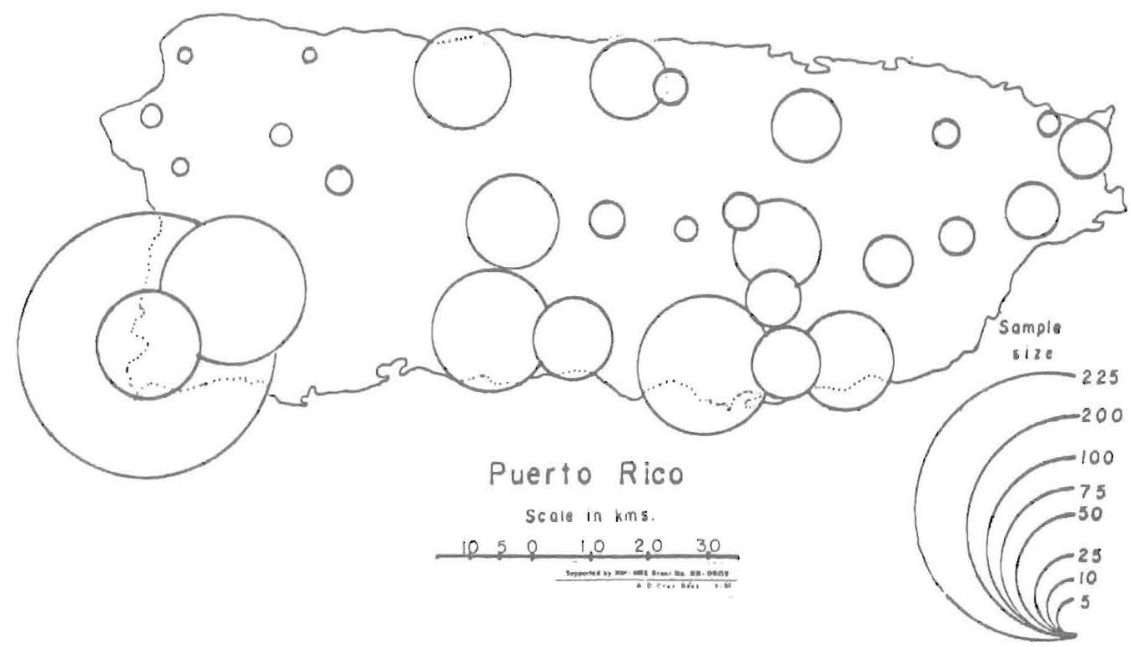

FIG. 1.-Location and size of goat samples.

sampled. All 11 goats positive with $F$. hepatica grazed in lowland wet pastures. On a small farm in Luquillo, located near a stream, two out of only three goats were positive with $F$. hepatica. Three goats with fascioliasis were found on a wet farm in the Boquerón area, and in Salinas three more positive goats were also found on a wet farm.

Figure I shows the location and size of the goat samples surveyed. The largest sample was obtained from the southwestern end of the Island, where a large number of goat farms were located.

More than half $(68.7 \%)$ of the goats sampled harbored more than one parasite concurrently (fig. 2). One hundred and forty-two goat stool samples showed no parasite eggs, and 98 had eggs of only one parasite species.

Concurrent infections with two or more helminths were found in 529

${ }^{3}$ Frame, A. D. and Bendezú, P. unpublished data. 
goats sampled. In each of 126 samples, eggs of two parasites were found. The highest number of goats, 205, showed concurrent infections with three parasites. In 114 goats, four different helminths were found per goat, and 63 goats had five different helminths. Six goats had seven helminths each, and one goat was found with eight different parasites.

In spite of the worm burden found in the goats sampled most of the animals appeared in average condition. Few, however, were viewed as

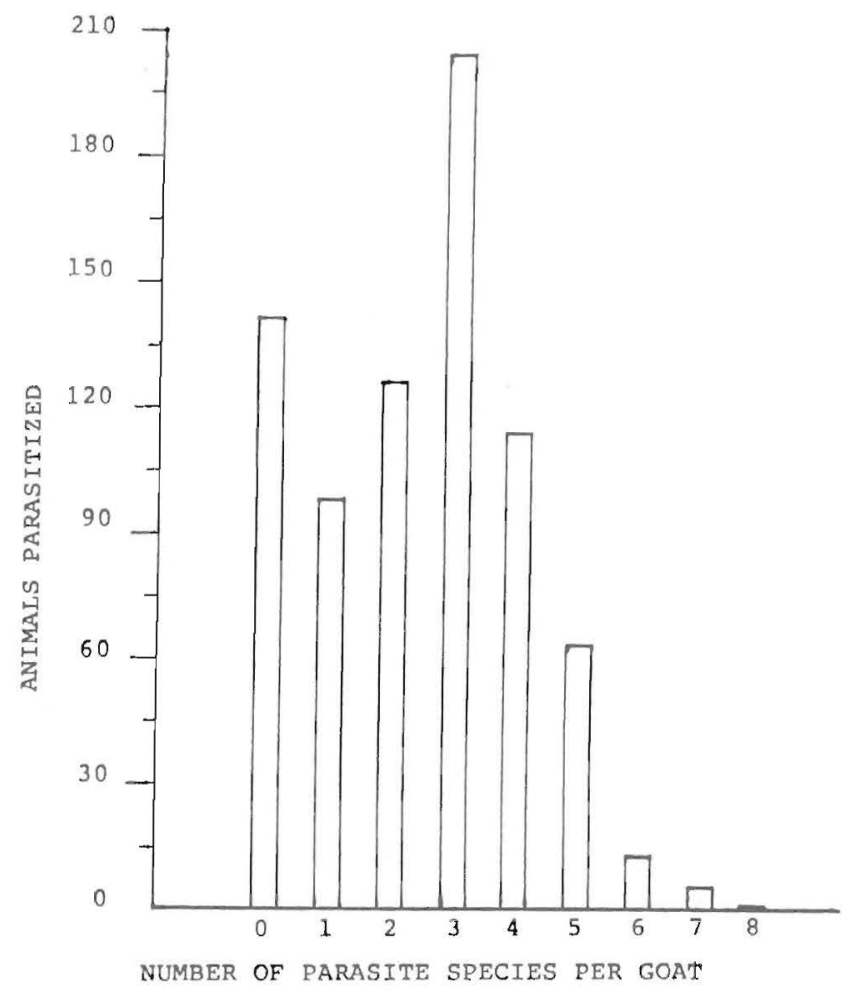

FIG. 2.-Parasite burden.

being "grade A" quality. Heavy worm burdens are known to stunt growth, decrease weight gain, and decrease milk production because of lowered feed efficiency and blood loss (13). Economic losses suffered by farmers because of parasitism are bound to affect the farmer as well as the community in general if not curbed.

\section{RESUMEN}

Exámenes fecales de 769 cabras de 48 fincas en 30 municipies de Puerto Rico realizados en el año 1981 demostraron que 10 helmintos de 
diferentes especies eran comunes a estos mamíferos domésticos, siendo $1.43 \%$ de estas muestras positivas a Fasciola hepatica. Para los otros parásitos el porcentaje fue el siguiente: Oesophagostomum columbianum $65.67 \%$, Haemonchus contortus $56.31 \%$, Bunostomum trigonocephalum $46.94 \%$, Chabertia ovina $24.57 \%$, Trichostrongylus capricola $15.60 \%$, Ostertagia circumcincta $14.43 \%$, Trichuris ovis $10.14 \%$, Moniezia expansa $6.39 \%$ y Cooperia curticei $2.21 \%$.

El bajo porcentaje de $1.43 \%$ de infección de $F$. hepatica en cabras contrasta con la alta infección de $65 \%$ en el ganado lechero (10). Con $H$. contortus sucede lo contrario, encontrándose $56.31 \%$ de infección de este parásito en cabras y $17.7 \%$ en vacas lecheras.

\section{LITERATURE CITED}

1. Bagué, J., 1921. La cucaracha del cerdo. Departamento de Agricultura y Trabajo, Circ. 49.

2. Brown, H. W., 1975. Diagnosis of Parasitic Diseases, Basic Clinical Parasitology. 4th ed, New York: Appleton-Century-Crafts, pp. 334-36.

3. Chiriboga, J., De León, D. and Rodríguez-Frias, J., 1980. Epidemiology of Fasciola hepatica infestation in dairy cattle at Dorado, Puerto Rico, J. Agric. Univ. P.R. 64: 93-106.

4. - - Ritchie, L. S. and de León, D., 1975. On the cryptobiosis of Lymnaea cubensis, the snail vector of Fasciola hepatica in Puerto Rico, J. Agric. Univ. P.R. 59: 236-37.

5. De León D., Chiriboga, J., Parra, D. and Llavona, M., 1975. Diferential diagnosis of infection by Fasciola hepatica and Cotylophoron cotylophorum in cattle and snail hosts, J. Agric. Univ. P.R. 59: 129-32.

6. - - Quiñones, R. and Hillyer, G. V., 1981. The prepatent and patent periods of Fasciola hepatica in cattle under Puerto Rican conditions, J. Parasitol. 67 (5).

7. - - Ritchie, L. S. and Chiriboga, J., 1972. Fascioliasis in dairy cattle in the Rio Plata basin of the Dorado area, Puerto Rico, J. Agric. Univ. P.R. 56: 88-90.

8. Frame, A. D., Bendezú, P., 1978. Bovine Fascioliasis in Puerto Rico, J. Parasitol., 64: 136.

9. - - - - Mercado, H., Otiniano, H., Frame, S. J. and Flores, W., 1979. Increase of bovine fascioliasis in Puerto Rico as determined by slaughterhouse surveys, J. Agric. Univ. P.R. 63: 27-30.

10. - - - - Rivera-Ortiz, C. I., Valentin, R. and Diaz-Rivera, J., 1978. Fasciola hepatica in dairy cattle in Puerto Rico in 1978, J. Parasitol., 66: 698-99.

11. Hillyer, G. V., 1981. Fascioliasis in Puerto Rico: A Review, Bol. Asoc. Med. P. R., 73 (3).

12. Rivera-Anaya, J. D. and Martinez de Jesus, 1952. The extent of liver-fluke infestation of cattle in Puerto Rico (A slaughterhouse survey), Agric. Exp. Stn. Univ. P. R. Bull. 107.

13. Soulsby, E. J. L., 1977. Helminths, Arthropods and Protozoa of Domesticated Animals, Lea and Febiger, Philadelphia.

14. Thienpont, D., Rochette, F. and Vanparijs, O. F. J., 1979. Diagnosing Helminthiasis through Coprological Examination, Janssen Res. Found., Beerse, Belgium.

15. Volkenberg, H. L. van, 1929. Report of the parasitologist: Liver flukes, Rep. P. R. Agric. Exp. Stn. pp. 36-7.

16. _-, 1930. Report of the parasitologist. Rep. P. R. Agric. Exp. Stn., pp 26-29. 
506 JOURNAL OF AGRICULTURE OF UNIVERSITY OF PUERTO RICO

17. _- 1934. Parasites and parasitic diseases of cattle in Puerto Rico, P. R. Agric. Exp. Stn. Bull. 36.

18. _ _, 1935. Parasites and parasitic diseases of horses in Puerto Rico, P. R. Agric. Exp. Stn. Bull, 37.

19. _—, 1936. Parasites and parasitic diseases of swine in Puerto Rico, P. R. Agric. Exp. Stn. Bull. 38. 